leading cause of death in 1998, with rate of 5.8 per 1000 live births. Although the IMR due to congenital anomalies was almost the same in 1998 and 2008, this cause ranked first as cause of death in 2008 together with prematurity. In conclusion, the reduction of IMR in Brazil implicates in a different distribution of causes of death and different challenges to the health system.

\section{P1-154 GUIDELINES FOR MONITORING SOCIOECONOMIC INEQUALITIES IN HEALTH: LESSONS FROM SCOTLAND}

doi:10.1136/jech.2011.142976d.47

1,2 J Frank, ${ }^{1,2}$ S Haw. ${ }^{1}$ Scottish Collaboration for Public Health Research and Policy, Edinburgh, UK; ${ }^{2}$ University of Edinburgh, Edinburgh, UK

Introduction This paper presents 'best practice' guidelines for population monitoring of health status by socio-economic position (SEP), using routinely collected data.

Methods We reviewed published sources to identify best practices in analytic methods and reporting of population health inequalities by SEP. We selected as our case-study three recent "cutting-edge" reports on health inequalities from the Scottish Government, analysing the following categories of routinely collected outcomes: natality (low birth weight rate-LBW); adult mortality (all-cause, coronary heart disease (CHD), alcohol-related, cancer); cancer incidence; healthy life expectancy at birth; and "mental health \& well-being score".

Results The most commonly unmet criterion, across these routinely collected outcomes, was 'prompt reversibility/sensitivity to change.' This is because most mortality events occur in later life, and LBW rate has now become obsolete as a sole indicator of perinatal health. Other outcomes were judged to fail other criteria: alcohol-related mortality after mid-life (probable 'reverse causation'); all cancer sites' incidence and mortality (heterogeneity of SEP gradients across sites, as well as long latency); and mental health \& well-being (uncertain responsiveness to feasible interventions).

Conclusions Even state-of-the-art reports on health inequalities by SEP are losing their relevance for most policy-makers, because they focus on routinely collected outcomes that are not very sensitive to change. We argue that more 'upstream' outcomes are required, which: occur earlier in the life course; can be changed within a halfdecade by feasible programmes and policies of proven effectiveness; accurately reflect individuals' future life-course chances and health status; and are strongly patterned by SEP.

\section{P1-155 LIFE-LIMITING \& LIFE-THREATENING ILLNESS IN CHILDREN AND YOUNG PEOPLE IN ENGLAND: HOSPITAL USAGE BY ETHNICITY}

doi:10.1136/jech.2011.142976d.48

${ }^{1} \mathrm{~L}$ Fraser, ${ }^{*}{ }^{2} \mathrm{M}$ Miller, ${ }^{3} \mathrm{R}$ Hain, ${ }^{2} \mathrm{~J}$ Aldridge, ${ }^{1} \mathrm{P}$ McKinney, ${ }^{1} \mathrm{R}$ Parslow. ${ }^{1}$ University of Leeds, Leeds, UK; ${ }^{2}$ Martin House Children's Hospice, Wetherby, UK; ${ }^{3}$ University of Cardiff, Cardiff, UK

Aims To develop an ICD10 coding framework to identify children and young people with life-limiting or life-threatening disease (LLLT). To use this framework to estimate hospital usage of patients with LLLT using Hospital Episodes Statistics (HES).

Methods Data from Martin House Children's Hospice was used to develop an ICD10 coding framework. A four digit ICD10 code was then assigned to each diagnosis and a final list of codes was compiled and completed by adding other appropriate codes including all malignant oncology codes. An extract of inpatient (2000-2010) HES data were requested where one of these ICD10 codes appeared in any diagnostic category in any patient aged under 25 years at admission.

Results The final ICD10 framework compiled consisted of 781 four digit ICD10 codes. Malignant oncology codes accounted for 445 codes with congenital malformations, deformations and chromosomal abnormalities having 90 codes. This was a marked year on year increase in episodes with a diagnosis of LLLT from 142614 episodes in 2000/1 to 210748 episodes in 2009/10 and the proportion of episodes for patients of a South Asian background increased from $8.6 \%$ in $2000 / 1$ to $12.4 \%$ in $2009 / 10$ while the black minority patients remained static ( $4.5 \%$ to $4.3 \%$ ).

Conclusion Children and young people with a LLLT have a marked increase of inpatient hospital stays from 2000 to 2010. There is an increase in the proportion of these episodes from children and young people with a South Asian background.

\section{P1-156 FALLS RISKS FACTORS AT HOME IN CHILEAN OLDER PEOPLE LIVING IN THE COMMUNITY}

doi:10.1136/jech.2011.142976d.49

${ }^{1} \mathrm{~A}$ F García, ${ }^{*} \mathrm{H}$ Sánchez, ${ }^{2} \mathrm{~L}$ Lera, ${ }^{2} \mathrm{X}$ Cea, ${ }^{2} \mathrm{~F}$ Salas, ${ }^{2} \mathrm{C}$ Albala. ${ }^{1}$ School of Public Heath, University of Chile, Santiago, Chile, ${ }^{2}$ Institute of Nutrition and Food Technology, University of Chile, Santiago, Chile

Introduction Older adult (OA) falls are a major public health problem being a main cause of disability and morbidity ( $30 \%$ of prevalence around the world), involving an extensive use of health services, and higher costs. Latin American data (2000) show higher prevalence of multiple falls among Chilean (20.3\%) and Mexican (19.5\%) elders than in the Region $(10 \%-15 \%)$. In Chile (2006), major part of the accident among elderly occurs at home (56\%). The aim is to study the association between risks factors at home and falls among Chilean OP. Methods Data are from National-Survey-of-Dependency-ChileanOP. 4762 representative sample community dwelling adults $61-101$ y (38.8\% men; 18\% rural) were interviewed in 2009/2010. Logistic regression analysis was used to estimate association between falls and risks factors at home.

Results Falls prevalence in the last year is $27.7 \%$ (CI 25.4 to 30.1 ); higher among women (31.9\%; CI 28.6 to 35.4), and those with poor eyesight (31.4\%; CI 28.4 to 34.6 ). Falls risks factors most present at home were insufficient light (94.5\%; CI 92.7 to 95.8 ) lack of handle in the toilette (89.3\%; CI 87.5 to 90.9), and in the shower (81.9\%; CI 78.7 to 84.7 ). Around $40 \%$ of the interviewed perceived the need to have a handle in both toilette and shower. After adjusting by age $(O R=1.01 ; p=0.003)$, being female $(O R=1.77$; $\mathrm{p}<0.001)$, living in rural-area $(\mathrm{OR}=1.14 ; \mathrm{p}=0.117)$, poor eyesight $(\mathrm{OR}=1.39 ; \mathrm{p}<0.001)$; falls were significant associated to insufficient light at home $(\mathrm{OR}=1.44 ; \mathrm{p}=0.021)$; and the perception of need handle in the shower $(O R=1.29 ; p=0.026)$ and toilette $(O R=1.40 ; p=0.004)$. Conclusion Prevention recommendations for falls among noninstitutionalized OP not only should include reduction of hazards (such as insufficient light) but also the installation at their homes of devices to avoid falls.

\section{P1-157 ARTERIAL HYPERTENSION: PSYCHOSOCIAL FACTORS AND RISK OF DEVELOPMENT DURING THE PERIOD OF 20 YEARS IN MEN 25-64 YEARS OF AGE IN RUSSIA}

doi:10.1136/jech.2011.142976d.50

${ }^{1,2}$ V Gafarov, * 1,2E Gromova, ${ }^{1,2}$ I Gagulin, ${ }^{1,2} \mathrm{~A}$ Gafarova. ${ }^{1}$ Collaborative laboratory of Epidemiology Cardiovascular Diseases Siberian Branch of the Russian Academy of Medical Sciences, Novosibirsk, Russia; ${ }^{2}$ Institute of Internal medicine the Siberian Branch of Russian Academy of Medical Sciences, Novosibirsk, Russia

We aimed to investigate the influence of psychosocial factors on the risk of arterial hypertension (AH) development over a 20 year period in men aged 25-64 years in Russia.

Materials and Methods Within the WHO program 'MONICA' psychosocial factors were examined in a representative sample of 
men aged 25-64 years old at 3 time points (1984, 1988 and 1994). Total sample was 2149 persons. The period of study was 10-20 years. Incident cases of AH were counted and Spilberger's test for estimation of personal anxiety (PA) was used. Coxproportional regression model was used for an estimation of RR.

Results During 20 years of investigation the incidence of $\mathrm{AH}$ was $16.9 \%$. High levels of personal anxiety (HLA) were present in $57.4 \%$ of the group with incident $\mathrm{AH}$. Incident $\mathrm{AH}$ with HLA was significantly higher in several subgroups: single, divorced and widowed men; incomplete secondary and primary education; men undertaking hard physical work. The RR of $\mathrm{AH}$ development during the first 5 years of observation in the HLA group compared to average level of anxiety (ALA) was 6.8 times higher (95\% CI 3.2 to 14.2; $\mathrm{p}<0.05$ ); in 10 years the risk was 5.0 times higher $(95 \%$ CI 2.9 to $11.8 \mathrm{p}<0.05)$ higher, and in 20 years it was 1.8 times higher $(95 \% \mathrm{CI}$ 1.1 to $3.2 \mathrm{p}<0.05)$.

Conclusion Personal anxiety should be considered in the development of $\mathrm{AH}$.

\section{P1-158 POLISH SURGICAL STAFF AND POST-VACCINATION TESTING TO DOCUMENT IMIMUNITY AFTER HBV VACCINATION: A CROSS-SECTIONAL SEROSURVEY}

doi:10.1136/jech.2011.142976d.51

${ }^{1}$ M Ganczak, ${ }^{*}{ }^{1}$ Z Szych, ${ }^{2}$ M Korzeń. ${ }^{1}$ Pomeranian Medical University, Szczecin, Poland; ${ }^{2}$ Westpomeranian University of Technology, Szczecin, Poland

Hepatitis B vaccination is recommended for HCWs but has a nonresponse rate of $5 \%-32 \%$. In Poland there is no standardised postvaccination protocol to confirm immunity.

Objective To determine the fraction of those who were previously vaccinated but not checked for serologic evidence of hepatitis $B$ immunity and to assess anti-HBs levels in that group by an anonymous cross-sectional sero-survey.

Methods surgical staff from 16 randomly selected hospitals in West Pomerania, Poland surveyed July 2010-January 2011.

Results of 488 participants (49 males, 439 females, Me age 42 years), in $361(74.0 \%$; $95 \%$ CI 69.9 to $77.7 \%)$ anti-HBs status was not determined after the basic course of HBV vaccination. Five per cent of those showed anti-HBs titre of $0.0 \mathrm{mIU} / \mathrm{ml}$ ( 6 of 9 given booster doses developed anti-HBs $>10 \mathrm{mIU} / \mathrm{ml}$ ) and $7.2 \%$ showed anti-HBs titre of $0.1-10 \mathrm{mIU} / \mathrm{ml}$. The multivariate logistic regression model revealed that working in a teaching hospital was associated with a smaller odds of not being checked for serologic evidence of immunity after $\mathrm{HBV}$ vaccination (OR 0.22 , 95\% CI 0.14 to 0.35 ; $\mathrm{p}<0.0001)$.

Conclusions The majority of surgical staff do not confirm immunity after the basic course of HBV immunisation. Working in other than teaching hospital is related to increased odds of not confirming immunity. It is unclear whether $5 \%$ surveyed who showed no serologic evidence of hepatitis B immunity are non-responders, lost immunity, or retained anamnestic potential. Lack of booster vaccination response in 3/9 subjects suggests non-responders Therefore, strict post-vaccination testing to document immunity is crucial to detect non-responders among surgical staff constantly exposed to blood.

\section{P1-159 INCOME AND ACCESS TO MEDICINES IN BRAZIL, 2008-2009}

doi:10.1136/jech.2011.142976d.52

L Garcia,* A Pacheco, L Santana, L C Magalhães, M Stivali, C Santos. Institute for Applied Economic Research (IPEA), Brasilia, Distrito Federal, Brazil

Introduction The Brazilian healthcare system is universal and provides pharmaceutical assistance. This paper investigates income disparities in public provision and out-of-pocket spending on medicines in Brazil.

Methods Prevalence of public provision was estimated using data from the National Household Sample Survey (PNAD-2008) (99\% CIs). The mean spending of families on medicines (Brazilian Real-R\$) and the proportion of this spending in relation to the family income were estimated using data from the Family Budget Survey (POF-2008/2009). Samples were divided in deciles of monthly family income per-capita.

Results Among people who had a drug prescription in the 2 weeks preceding the interview, $45.8 \%(45.5 \%-47.1 \%)$ received all or part of the medicines without paying, $62.9 \%(60.3 \%-65.4 \%)$ in the bottom income decile, and $15.8 \%(14.1 \%-17.7 \%)$ on the top. Among those who reported life-long use of medicines, $51.6 \%(51.1 \%-52.1 \%)$ received part or all without paying, $66.2 \%(63.9 \%-68.3 \%)$ in the bottom decile, and $17.8 \%(16.8 \%-18.9 \%)$ on the top. The mean monthly per-capita spending on medicines was $\mathrm{R} \$ 4.42$ in the bottom decile and $\mathrm{R} \$ 58.11$ on the top.

Conclusion While the public provision of medicines was about four times higher in the bottom decile than in the top and the out-ofpocket spending was 13 times higher in the top decile, the proportion of spending on medicines in relation to the family income was three times higher in the bottom decile. Although the public policy is equitative, the burden of spending on medicines is too high on poorer families.

\section{P1-160 HEALTHCARE EXPENDITURE IN THE LAST YEARS OF LIFE FOR OUT-OF-HOSPITAL MEDICARE BENEFITS SCHEDULE FUNDED SERVICES IN WESTERN AUSTRALIA: A POPULATION-BASED DATA LINKAGE STUDY}

doi:10.1136/jech.2011.142976d.53

${ }^{1,2} \mathrm{R}$ Moorin, ${ }^{1} \mathrm{D}$ Gibson, ${ }^{*}{ }^{1} \mathrm{D}$ ' A Holman. ${ }^{1}$ Curtin University, Perth, Western Australia, Australia; ${ }^{2}$ University of Western Australia, Perth, Western Australia, Australia

Introduction Persistent debate over the relationship between timeto-death, age and healthcare expenditure may be the result of overgeneralised modelling. Single-population total health service utilisation models may not take into account differing patterns of use between out-of-hospital services. We explored the relationship between time-to-death, age and healthcare expenditure for government funded out-of-hospital services in last years of life to determine effects of service type and the stability of this relationship over time.

Methods Records of all deaths in Western Australia from 1990 to 2004 extracted from the mortality register and linked to records from the Medicare Benefit Scheme. Claims 5 years prior to death were identified from all Medicare Benefit Scheme claims originating in Western Australia between 1984 and 2004. Out-ofhospital costs were assigned to all services within 5 years of death from five major causes using Medicare Benefit Scheme costing information.

Results Out-of-hospital healthcare expenditure increased for primary care services during last 2 months of life. A similar trend was observed in specialist services and diagnostic and therapeutic services, however an earlier increase in expenditure occurred during the penultimate year before death.

Conclusion Primary care service cost patterns varied for specialist services and diagnostic and therapeutic services for both time to death and age. Significant differences in relationship between time to death, age and healthcare expenditure were identified between service types, highlighting potential shortcomings in using single population models to predict future healthcare expenditure. 